\title{
DEVELOPMENT OF LEAN CONSUMPTION CONCEPT IN IMPROVING PROCUREMENT PROCESS OF NEW ITEM AND PROJECT PROCUREMENT
}

\author{
Damayanti Deasy ${ }^{\star}$, Syah Tantri Yanuar Rahmat, Sunaryanto Ketut \\ Faculty of Economics and Business, University of Esa Unggul, Indonesia \\ *E-mail: deasydamayanti@yahoo.com
}

\begin{abstract}
The concept of Lean Consumption Map was first popularized by (Jones, 2005). Lean consumption is how to emphasize a new focus on "performing more than less". Many organizations seek to avhieve effeciency and effectivity in their supply chain. One method that organizations use to achieve efficiency is the adoption of clean processes in their supply chain function. These processes aim to identify and eliminate the futile activities of operations and emphasize the need to continually improve performance. The concept of Lean Consumption Map is a development of Lean concept that comes from Toyota Production System (TPS), was popularized by Taiichi Ohno and assisted by Shigeo Shingo in 1956 at Toyota company and later combined with the Six Sigma method introduced by Motorolla company after thirty years later, making Lean Six Sigma so popular as a method of improvement in accordance with the demands of the business world. Initially known as Lean Production, now many have been developed to be applied in various other industrial sectors such as Lean Manufacturing, Lean Supply Chain, Lean Service, Lean Hospital, Lean Finance, Lean Human Resource, Lean Municipal, Lean Office, Lean Military. Along with the need for lean development concept, by seeing the successful implementation of Lean consumption in the service sector, the same can also be applied to the procurement process. Based on the results study, Lean consumption can be applied with the aids of DMAIC (Define, Measure, Analyze, Improve, Control) and LCM (Lean Consumption Map) in improving the procurement process for the procurement of new items and projects.
\end{abstract}

\section{KEY WORDS}

Lean consumption, procurement, DMAIC

In 1990, a five-year study on the future of cars produced a book on revolutionary manufacturing practices developed by Toyota Motor Co. entitled The Machine That Changes the World (co-authored with Daniel Roos, director of the MIT International Vehicle Program, and Daniel Jones, director of the European program), the book was a call to wake up the company, until it became the home of the world's largest vehicle manufacturer.

For the first time, the world in general discovered secret recipes that Toyota used to grow endlessly in the global market. Obviously, Womack was very impressed with Toyota's lean manufacturing system (so called as such because the secret lies in using fewer things: labor, material, and money) that finally it became a lean spreader in 1997, when he founded the (non-profit) Lean Enterprise Institute in Cambridge, Massachusetts. Since then, Womack has traveled the world to spread lean. Recently in India for a seminar, Womack spoke with R. Sridharan from BT about the benefits and challenges of being lean (Sridharran, 2008).

Lean which was originally applied in the manufacturing industry, has now developed in the service industry. For example in hospitals, many mistakes can be helped by applying Lean, for example errors in calculating doses, errors in drug administration, errors in interpreting prescriptions, confusion about drug names, poor labeling, wrong drug administration, administration of patient payments that are wrong and so on (Syukron et al., 2013).

Studies on lean have also been carried out by many researchers (e.g. Widiantoro, 2015; Lizasoain et al., 2015; Arfmann and Topolansky, 2014; Procter and Radnor, 2014; Maleyeff, 2014; Nadeau, 2017; Rüttimann et al., 2014; Leite and Vieira, 2015; Arafeh, 2016; Drake et al., 2013; Berenyi and Banhegyesi, 2015; De Sousa et al., 2014). (Arfmann, 2014) 
stated that Lean is only suitable in the manufacturing or service industries. Moreover, based on the research described previously, it was found that the Lean Consumption Mapping (LCM) method had not been used to show improvement in the conditions of Current State and Future State. The researcher has also never received research using Lean Consumption Mapping (LCM) which is very suitable to describe the condition of Current State and Future State for public services or services. The research studied by (Widiantoro, 2015) forced the use of VSM (value stream mapping) tool in the process of procurement of goods and services. Lean's research with internal customers has also not been found, nowadays there are many researches on Lean implementation with external customers. Here is a study of the application of Lean thinking (Sunaryanto and Syah, 2019) where customers are people not employees of Bapenda. The following is also a study of Lean Government conducted on external customers (e.g. Hadriyanto and Syah, 2019; Ginanjar and Syah, 2019; Hartanto and Syah, 2019;). Likewise with research (Artadi and Syah, 2019) regarding lean service for purchasing with external customers.

Procurement of goods / services in an organization or company is a routine activity that is always carried out for the continuity of an operational process of an organization or company. According to (Anderson et al., 2012) the cost of procurement of goods / services incurred by the Procurement Department reaches $25 \%-60 \%$ of the company's total costs, depending on the type of industry. This fact suggests that Procurement needs to be managed comprehensively in order to get optimal savings. The Procurement Function must be in line with the company's business strategy and be able to align between the needs of the organization and the market's ability to supply goods / services.

This needs to be done so as not to lose business momentum that can cause losses. Delay in the procurement of goods, especially new items will have an impact on market dominance, the company's image as a follower not an innovator.

To achieve these objectives companies must be able to find and choose the right supplier, by selecting suppliers, and no less important is to control supplier performance. A good procurement process must be able to process the information available relating to the required procurement in order to produce the best transactions even in critical conditions. The Procurement Function must be in line with the company's business strategy and be able to align between the needs of the organization and the market's ability to supply goods / services (Lizasoain et al., 2015).

In general, the problem that arises is the long lead time in the process of procurement of goods and services for new goods or projects due to the lack of understanding of the level of urgency of these items both in terms of the procurement team, users and suppliers. This phenomenon can be categorized as waste which results in inefficiencies in the process of procurement of goods / services. One method that can be used to overcome waste in the process of procurement of goods / services is the Lean method through analysis of waste in the process flow. The Lean process is carried out through five steps namely (1) defining value for customers, (2) establishing a Lean Consumption Map, (3) making it "flow", (4) "pulled" by the customer, and (5) trying hard to achieve the best (Jones, 2005).

Based on consideration of the results of previous research and the results of the Research Desk related to the Lean Consumption method, this is what makes the researcher wanted to conduct research on the analysis of the effectiveness of applying the Lean Consumption concept in Indonesia with customers as internal parties. Of course, by using the Lean Consumption Mapping (LCM) tool, it will further increase knowledge both in terms of researchers, academics, local government and the wider community. It is hoped that this will become a reference for other researchers in the future.

The purpose of this study is to identify and reduce waste in the process of procuring goods and services for new items / projects. In addition, the purpose of this research action is to support continuous learning from organizational members. The researcher created and conducted experiments on a real problem, which was assisted by practitioners from the organization in the re-education process by forming new actions. Besides that through this research, it is expected to be able to create proactive support from the supplier side that is 
also in line with the Lean Consumption concept which is certainly very profitable in terms of the company's business in broad terms.

\section{LITERATURE REVIEW}

In general, the stages carried out in the process of procurement of goods / services at PT. Strawland can be illustrated in figure 1.
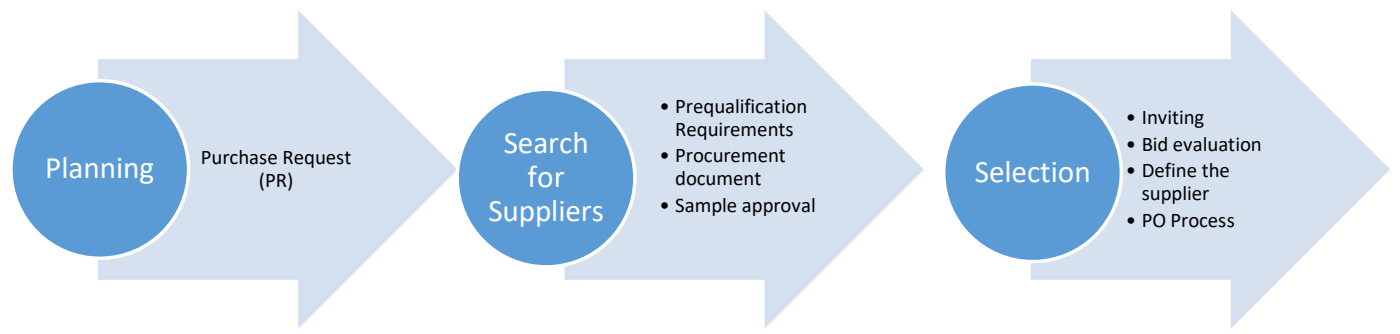

Figure 1 - Stages of goods and services procurement

The development of lean concept originated from the Toyota Production System (TPS), which originated in Japan after the Second World War developed by Taiichi Ohno and assisted by Shigeo Shingo in 1956. At this point, Toyota operated in an environment that has limited resources when it comes to land as well as technology, iron investment and finance. These special circumstances made Toyota changed efficiency in their own way in improving performance in terms of QCD (Quality, Cost, Delivery) and put forward new basic principles for overcoming scarce resources. Lean's basic idea is to focus on flow efficiency rather than resource efficiency and to focus on customers, only produce what the customer wants, according to the customer's wishes, and when the customer wants it (Larsson, 2008).

Liker et al. (2006) suggested lean briefly means eliminating waste (waste / youth) in the entire process flow. Another term is NVA Time (Non Value Add Time) or time that has no added value. There are seven types of waste introduced by the term TIMWOOD. "T" stands for Transportation, which is a type of waste due to the activity of moving goods, raw materials (products), products and others from one place to another, even in close proximity throughout the process. "I" stands for Inventory, which is a type of waste due to excess raw materials, semi-finished products, or finished goods that cause long lead times, obsolescence, damage, Transportation and storage costs arise in the warehouse. "M" is an abbreviation of Movement, which is a type of waste due to excessive movement of employees during the process and does not provide added value to the product / service such as the activities of searching, piling up raw materials, taking, turning the body, stacking equipment and others. Walking around is also considered wasteful. Then "W" stands for Waiting, which is a type of waste due to workers waiting or not doing productive activities that can be caused by waiting for the next processing step, raw materials run out, machines or equipment is damaged, excessive machine capacity or there is a process that is not balanced. Then the first "O" stands for Overproduction, which is a type of waste due to producing goods / products earlier or in quantities more than what is needed by the customer. Producing earlier or later than needed results in other wastes, such as oversupply, storage, and transportation costs due to excess inventory. Inventories can be physical inventory or information queues. Then the next "O" stands for Overthinkinging, is a type of waste due to carrying out the stages of the process that are not needed in an ideal process. This inefficient processing is caused by several things such as partially damaged equipment, poor product design and so on. "D" stands for Defect, which is a type of waste due to the process carried out resulting in damaged / defective / failed products, reprocessing, replacing defective production, destruction of defective goods along with the time, costs and effort that must be incurred by the company.

An important aspect of Lean is mapping the flow of activities in order to identify which activities create value for customers, and which ones must be eliminated. The product must 
flow through the process at the same speed as the customer requested. This is takt time, which determines the speed of the manufacturing system or the speed of internal processes. In this way, customer needs create interest in the organization (Bergman et al., 2010). According to Wedgewood (2006), a pretty good explanation of the difference between the two strategies, and the motivation for combining them is if, simply, Lean sees what we shouldn't do and aims to erase it; Six Sigma looks at what we should do and aims to do it correctly at the first and every time, forever.

The concept of Lean Consumption Map was first popularized by (Jones, 2005). Lean Consumption is how to emphasize a new focus on "doing more with less". Many organizations are looking to achieve efficiency and effectiveness in their supply chains. There are various opinions about how organizations can achieve this. One method that organizations use to achieve efficiency is the adoption of clean processes in their supply chain function. These processes aim to identify and eliminate the futile activities of operations and emphasize the need to continually improve performance. Data from the APQC Open Standards Benchmarking in procurement shows that $27.5 \%$ of organizations have invested in developing Lean process for their procurement function and nearly $13 \%$ plan to invest in the development of Lean process in the next two years. Organizations that embrace lean initiatives must involve their employees in all aspects of Lean adoption to ensure that these individuals understand why change is being made and the potential benefits for the entire organization, this was stated by (Partida et al., 2014).

By investigating contingencies in applying Lean Consumption production to procurement, (Costantino et al., 2015) emphasized that the principle of Lean Consumption production needs to be translated and interpreted into procurement operations by making changes to match procurement operations, and this helps reduce what we spend in stock in time and money.

Lean consumption metric for the procurement process in procurement is basically not far from the metrics in other industries. According to Ross and Associates Environmental Consulting, Ltd (2009), metric is divided into two, namely process metric and organizational metric. There are five process metrics and two organizational metrics. The first process metric is Time, which is the time needed to produce a product / service and deliver it to the customer. The second process metric is Cost, which is the cost that can be saved both the cost of the product or process as well as the number of employees needed in the related process. The third process metric is Quality, namely measuring the quality of the product or service as an example of customer satisfaction and whether the documents are complete and accurate. The fourth process metric is Output (ie), i.e. monitoring the production lines or activities of the agent process. As an example of the number of licenses that have been completed. The fifth process metric is Thinking Complexities, which describes the level of complexity and original processes, such as the number of handovers between processes and stages in the process. While the first organizational metric is Lean Consumption Deployment (Application of Lean Consumption), which measures the status of the application of Lean Consumption in companies such as the number of Lean activities or training that has been carried out. The second organizational metric is Motivation / Morale, which measures employee satisfaction and staff retention as indicated by employee surveys and turnover rates.

Procurement is a process of activities carried out by an organization in realizing procurement, both in the form of goods and services. It is important that the goods / services obtained can be suitable and obtained at the best cost to meet the needs in terms of quality and quantity, time, and location. Purchasing is any activity in which the organization receives invoices from outside parties when procurement includes all activities to get products from vendors to their final destination(Cees et al., 2005).

The principle of procurement is the activity of receiving / acquiring and buying goods or services from outside parties (these outsiders can be individuals / companies providing services or goods needed by the company) with the main goal is how to obtain goods or services needed by the company with prices, after sales services, quality, best quantity according to the needs of the company / organization. The procedure of the purchasing 
process is to understand people who need goods and services. The next process is the selection of suppliers or main suppliers with two basic aspects such as potential suppliers and a list of all suppliers. Step 3 is usually called Purchase Order (PO). After placing an order, you need money to process the payment. The receipt of goods will verify the goods received from the supplier in accordance with the quantity of the purchase order document and provide information to the purchasing department. The Payment Department will verify the invoice based on the customer's request. Payments are made in accordance with the agreement which is a document that has been issued.

Research proposition is a logical relationship between two or more concepts summarized in the form of sentence statements. From the description of previous research, the proposition in this study is that Lean Consumption method can be applied and improve time efficiency in the process of procuring new goods and projects by saving time from the consumer side of the user while saving time from the service provider side, namely the procurement team. The second proposition that LCM and DMAIC are appropriate and structured methods for later use in the application of the concept of Lean Consumption in the procurement process.

\section{METHODS OF RESEARCH}

This study used qualitative research method with data obtained based on observations, document analysis and notes or reports. Qualitative research is inductive because it gets data in the field, empirical data. The researcher enters the field, studies the process or findings that occur in the field, records, analyzes, interprets and reports and draw conclusions from the process (Sugiyono, 2005).

Source of data came from primary and secondary data. Primary data obtained from direct observation of the process at PT. Strawland. And secondary data was obtained from the results of recording the relevant units and reviewing other documents. Research actions are defined as an approach in which researchers and research objects or informants work together in diagnosing problems and developing a solution based on a diagnosis (Bryman et al., 2007). PT. Strawland is a company engaged in the plastic industry, established since 1998, located in Jatake-Tangerang Industrial Estate.

Determination of informants in this study is the procurement team and user. Sampling was carried out from January to December 2018. In accordance with the research, the data collection was focused on identifying the procurement process of goods realized in the form of Value Added Assessment. Data on service process time was only used as supporting data. Observations were made during office hours, i.e. from 09.00-17.00 WIB.

In this study the data collection instruments used were observation guideline instruments, layout instruments (distance). Observation guideline instruments using data guidelines available at PT. Strawland, namely observation guidelines, document guidelines or notes, and other tools. Guidelines for observations contain guidance on observing the phenomena of activities in procurement, Standard Operating Procedures, Checklists, Cross Function Diagrams and so on. The second instrument is a layout instrument. Layout instrument (distance) using the conceptual guidelines of Lean consumption used starting with identifying problems, waste and the root causes are grouped into the overall procurement system (macro) and analysis at a smaller (micro) level at each facility. The data that has been collected by the researcher must be kept valid. The effort taken to maintain the validity of the data was to use data triangulation, namely triangulation of sources and triangulation of data collection methods (Moleong, 2009).

To get data on how the procurement process is carried out at PT. Strawland, an internal Thinking Measurement Tool (PMT) was used. PMT is designed to measure how much time is spent on a particular activity, in the total and average amount of time, to compare the overall results and find areas of improvement. This tool requires one person to observe the employee who works, and calculates the time in which the employee does the activity. During the study, a number of interviews and discussions were conducted with 
officers and other employees involved in the procurement department. Interviews were also conducted with several users.

This interview method was also used to explore problems or constraints that can cause time wastage. Interviews and discussions were used at a greater level to discuss proposed improvements to get input from officers and other employees and leaders in terms of how feasible the proposal can be realized, and to develop further proposals with other officers.

The next stages of the research are presented in Figure 2. This research was only carried out until the analyze phase. To continue the next stage, the participation of top management decisions is needed.

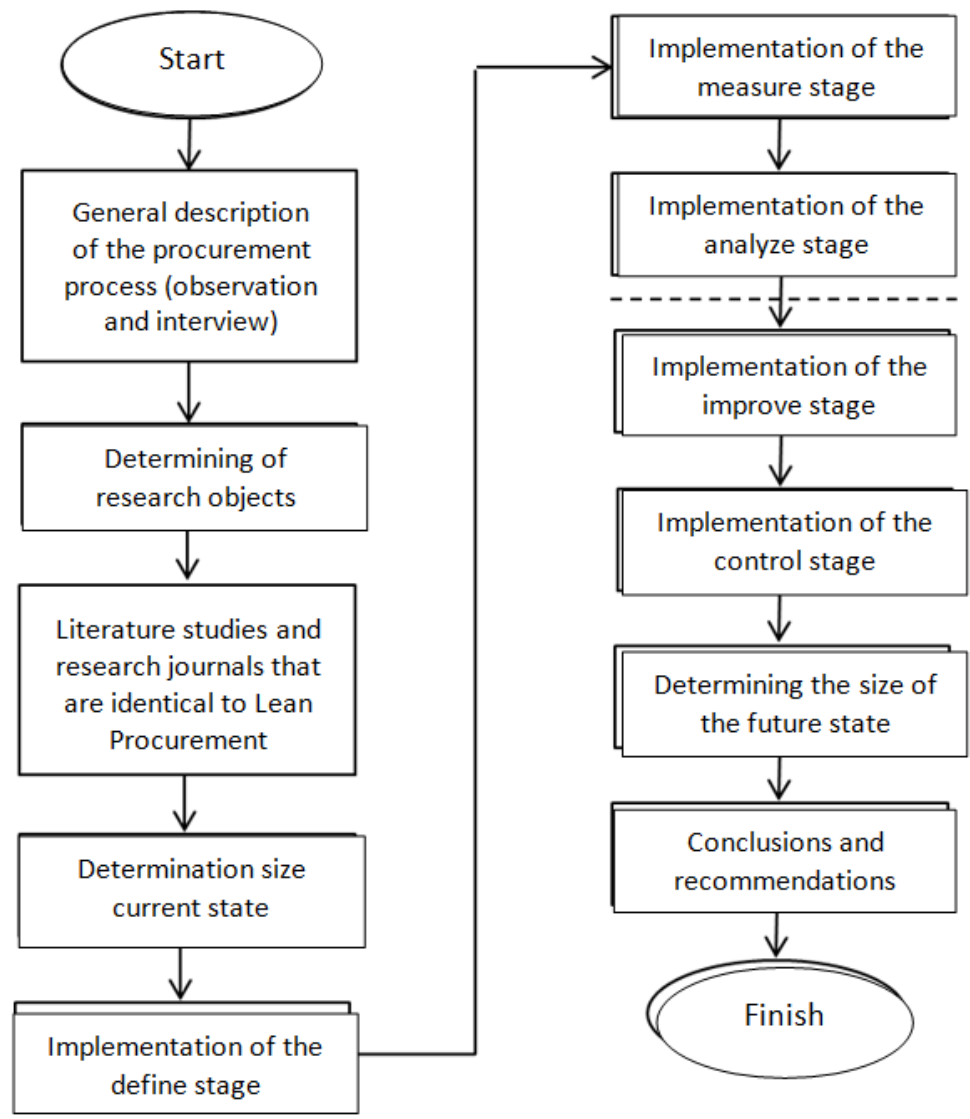

Figure 2 - Research Stages

The improvement method in Six Sigma for existing processes is called DMAIC and consists of five phases (Andersson et al., 2006). The first phase is "D" which is a continuation of Define, namely identifying the process or product that needs to be improved, preparing the project structure, and identifying the target desired by the customer. The second phase is "M" which stands for Measure, which identifies the most influential patterns, understands the process map and determines how to measure it. The third phase is "A" which is an extension of Analyze, i.e. identify and determine the root cause of the problem and the corrective steps to be taken. The fourth phase is "I" which stands for Improve, which is designing and testing the implementation of the most effective solutions. The fifth phase is " $\mathrm{C}$ " which stands for Control, which confirms that the solution is effective and ensures that it lasts long by setting new standards.

If $Y=f(x)$, then in Define phase, the outcome variable, "y", which needs to be corrected is identified, and y's performance is also estimated. Then move to the Measure phase, the input factor, " $x$ " that might affect $y$ is identified, and new detailed data about $y$ and $x$ are collected. In the Analyze stage, $x$ which affects $y$ is mapped, meaning that the relationship between the two is formed. The solution was designed in Improve phase, based 
on the relationships that exist in Analyze, and in the Control stage it is verified that improvement is achieved (Magnusson et al., 2003).

In 1991, Motorola made a certification in the form of a "Black Belt" for Six Sigma experts. This is the first time that a formal degree of Six Sigma certification has been granted. The levels of certification in Six Sigma are respectively: White Belt (basic), Yellow Belt (Intermediate), Green Belt (Advance), Black Belt (Expert) and Master Black Belt (Master). Then in 1995, the CEO (Chief Executive Officer) of the General Electric (GE) company, Jack Welch decided to implement Six Sigma at GE which was then widely spread throughout the world after hearing of the success of Motorolla and GE. (Syukron et al., 2013).

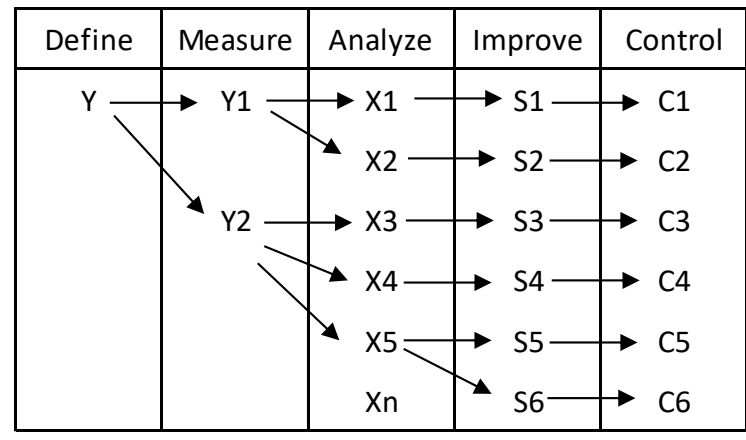

Figure 3 - DMAIC Method

The researcher used DMAIC measurement method (Define, Measure, Analyze, Improve, and Control). This method was combined with the Lean concept which aims to eliminate waste.

Define is the step to determine the measure of success of the implementation process and the limits that will be used in this project. The chosen measure of success is the average time of completion of service in each month based on the Checklist of documents and records using SIPOC tools (Supplier, Input, Process, Output, Customer) and Time Series Plot.

Measure is the stage to determine the focus of the problem by understanding the current process map (Current Process Map) based on Interview Guidelines, Observation Guidelines, Document Guidelines and other Tools. By using the Lean Consumption Map (LCM) tool, process map, cross function flowchart and VAA (value added assessment) the researcher will carry out mapping thus total consumer time performance (total customer time) and total provider time can be measured (total service provider time). Besides total time, the researcher measured the total value added time and total non-value added time both from the consumer and provider side. Consumer in this case is an internal employee of PT. Strawland namely the User / planner and provider is the procurement team.

Analyze is the stage of validation and determines the roots of the problems that directly affect the focus of the problem based on the Interview Guidelines, Observation Guidelines, Guidelines for Documents and other Tools. At the Analyze stage the researcher used FMEA tools (Failure Mode and Effect Analysis) to get the root of the problem that has a value of RPN (Risk Priority Number) which is at great risk to the focus of the problem.

Improve is the stage of determining the proposed improvement for each root cause by developing potential improvements that can come from published research, Lean reference books, Interview Guidelines and Observation Guidelines. These potential improvements were then validated with the IEM (Impact and Effort Matrix) tool. Potential improvements that get Zone I, Zone II and Zone III scores will be proposed improvements that will be validated in the improvement simulation process. The simulation process will use 60 sample data that will be a reference that the proposed improvement is effective or not, and at the same time see the effect of improving time in each process with the Lean Consumption Map (LCM) tool. Value Added and Assessment will be used to compare the value added activity against waste (waste). 
Control is the stage to determine the control measures of the results of the Improve phase that the positive influence during the Improve stage is continuously maintained and consistently implemented by the procurement team. The results of the Control stage are in the form of a Change Management Plan document in which there are changes to the SOP (Standard Operational Procedure), Training to employees, determining key parameters, determining process indicators or control indicators, OCAP (Out of Control Action Plan), Checklist or Audit.

\section{RESULTS OF STUDY}

The research used in this thesis was based on DMAIC cycle with the concept of thinking. This was chosen because the researcher had an understanding of the framework of the previous research and considered it to be very suitable when implementing the types of improvement projects. DMAIC is a continuation of Define, Measure, Analyze, Improve and Control.

As explained above this study describes the current condition as $Y$ which will be improved to $Y$ 'or future conditions through the DMAIC process. In this study the completion time data from the start of the activity, namely the User (planner) submits a request for goods through the PR Form to the Open PO process as an illustration of the present condition. Based on these data, it is known that the completion time can reach 18265 minutes.

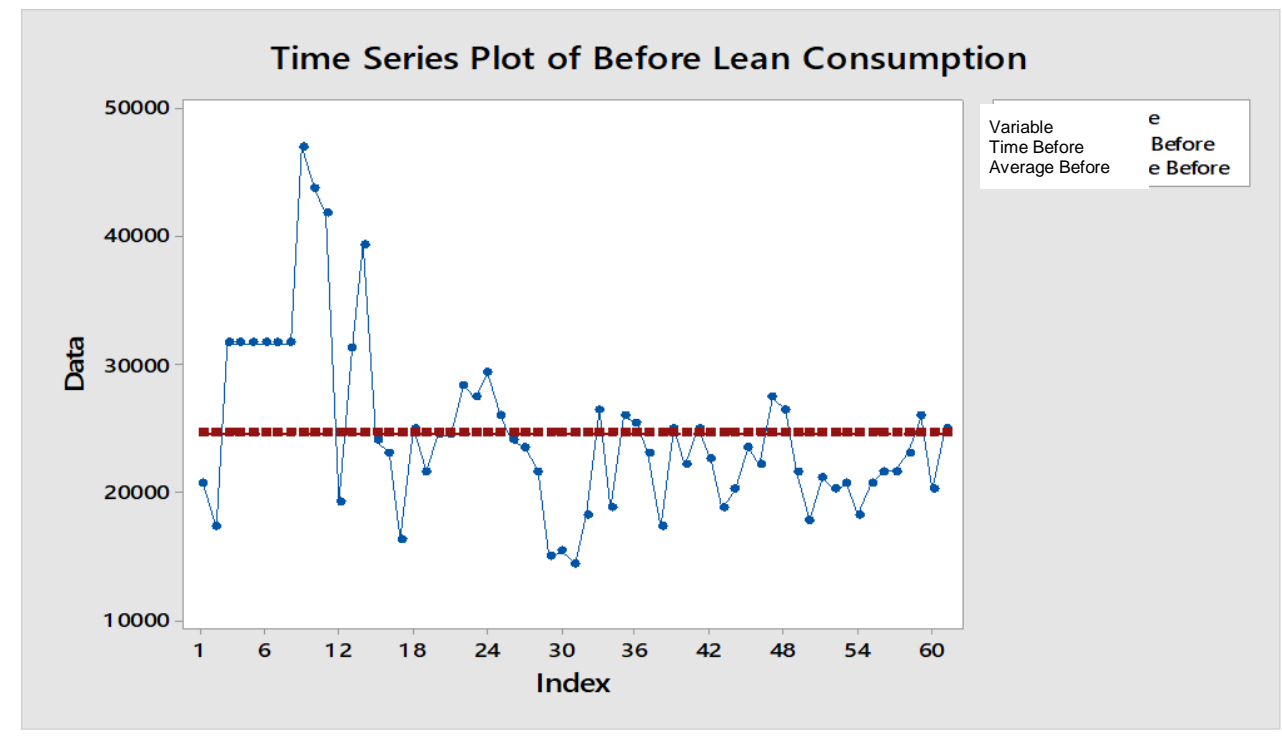

Figure 4 - Time Plot series before Lean Consumption

Based on the data above, the researcher determined the 9600 minute repair target, referring to the standard time determined by the KPI for the procurement of new goods and projects. Researchers assume that the process of procuring new goods and projects is not as long as it is in the data collected.

To explore this problem and achieve the above improvement target, the researcher determined the focus of the problem by understanding the current process map (Current Process Map) based on Interview Guidelines, Observation Guidelines, Document Guidelines and other Tools. By using the Lean Consumption Map (LCM) tool, the researcher will do the mapping so that it can measure the performance of total consumer time (total customer time) and total provider time (total service provider time).

The first step is to map the procurement process flowchart or Flow Chart. The flow starts with the submission of a PR form by the user, and then submits it to the Procurement team. Then the Procurement team will recap it PR and find vendors or suppliers on request. 


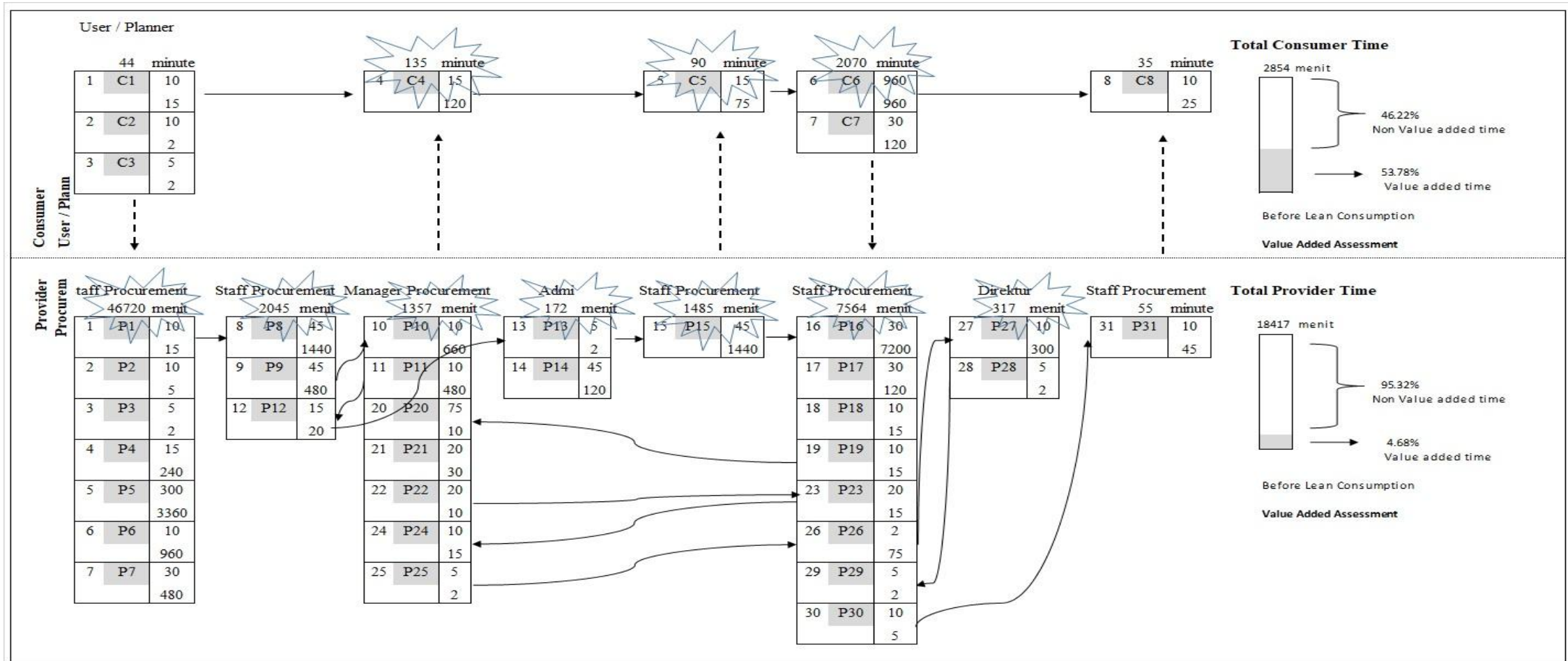

\begin{tabular}{|c|c|c|c|}
\hline & Journey to Submit PR Form & P12 & Receive validated files nad submit to admin staff \\
\hline 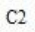 & Communicate with procurement staff & P13 & Receive validated vendor completeness files from procurement staff \\
\hline C3 & Handover of $P R$ form & P14 & Validated vendor registration \\
\hline $\mathrm{C} 4$ & Provide confirmation of the meting schedule & P15 & Arrange meeting schedules with suppliers to discuss samples \\
\hline & Provide confirmation of the meting schedule & P16 & Request samples to the user \\
\hline & Sample testing process & P17 & Provide samples to the user \\
\hline & Report trial sample results & P18 & Receive reports on trial results \\
\hline & Receive notifications for making Pos & P19 & Evaluate price quotes with Procurement managent \\
\hline & Receive PR form & P20 & Discussion of bidding and evaluation \\
\hline & Check the completion of the approval & P21 & Price negotiations with suppliers \\
\hline & Intitials on handover of $P R$ form & P22 & Define the supplier \\
\hline & Recap of PR documents & P23 & Make a PO and submit it to the Procurement manager \\
\hline & Perform vendor searches & P24 & $\mathrm{PO}$ signing \\
\hline & Make a visit and meeting appointment & $\mathrm{P} 25$ & Submit the signed PO to the Procurement staff \\
\hline & Price request process & P26 & Receive PO fies that have been signed by the manager and forvard them to the Director \\
\hline & Estabbish prequalification requirements & P27 & $\mathrm{PO}$ signing \\
\hline \multirow[t]{4}{*}{$\mathrm{Pg}$} & Checking the completeness of legality and & P28 & Submit the signed $\mathrm{PO}$ to the Procurement staff \\
\hline & validation documents by the Procurement & P29 & Receive PO files that have been signed by the Director \\
\hline & & P30 & Send Pos to suppliers by email fax \\
\hline & apleteness of legalit & & Provide notification on the making of $\mathrm{PO}$ to the users. planners \\
\hline
\end{tabular}

Figure 5 - LCM before Lean Consumption 
The next step after mapping with Flow Chart is to map the Lean Consumption Mapping. It aims to find out and assess activities with value added and non-value added activities. This Lean Consumption Mapping analysis is useful to find out waste in every activity both in terms of service users and service providers so that later it can be made improvements to activities that lack value added.

Table 1 - Value Added Assessment Sebelum Lean Consumption

\begin{tabular}{|l|l|c|c|}
\hline \multicolumn{2}{|c|}{ Description } & $\begin{array}{c}\text { Customer } \\
\text { (Consumption Time) }\end{array}$ & $\begin{array}{c}\text { Provider } \\
\text { (Provision Time) }\end{array}$ \\
\hline Total Time & (a) & 2374 & 18265 \\
\hline Value Added & (b) & 1055 & 822 \\
\hline Non Value Added & (c) & 1319 & 17443 \\
\hline$\%$ VA & $=($ b) $/($ a $) * 100 \%$ & $44.44 \%$ & $4.50 \%$ \\
\hline$\%$ NVA & $=($ c $) /($ a $* * 100 \%$ & $55.56 \%$ & $95.50 \%$ \\
\hline Value to Waste Ratio & $=($ b) $/($ c $) * 100 \%$ & $79.98 \%$ & $4.71 \%$ \\
\hline
\end{tabular}

Based on the results of Lean Consumption Mapping, it can be seen that from the total user service time needed to complete the process is 2374 minutes with a total value added of 1055 minutes or $44.44 \%$ while the total non-value added 1319 minutes or $55.56 \%$. While in terms of service providers the total time needed to complete the process is 18,265 minutes with a total value added 822 minutes or $4.71 \%$ while the total non-value added is 17,443 minutes or $95.50 \%$. In addition to the fact that high non-value added activities were found, it was also found that there were many activities that were waiting or waiting in line by service users, resulting in a waste of time.

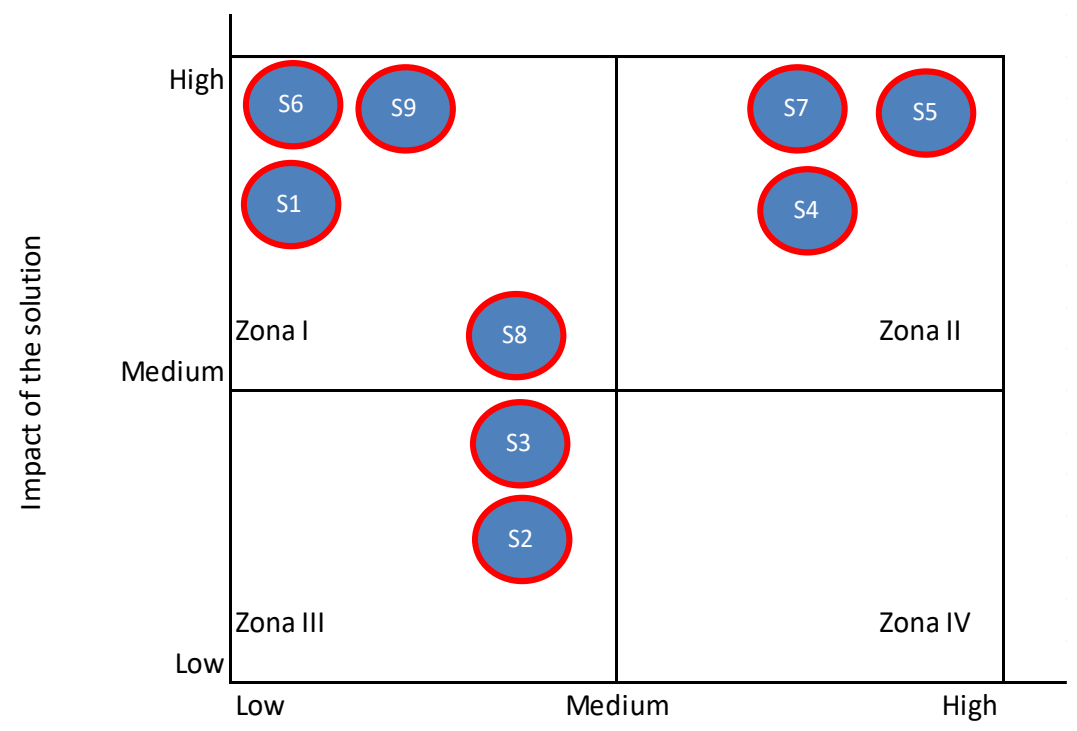

Effort required to implement

\begin{tabular}{|c|l|c|}
\hline No & \multicolumn{1}{|c|}{ Proposed Improvements } & Code \\
\hline 1 & Establish a standard processing time & S1 \\
\hline 2 & Make a follow up checklist & S2 \\
\hline 3 & Make internal communication media (email) & S3 \\
\hline 4 & Asking suppliers to provide Technical data sheets & S4 \\
\hline 5 & create an integrated PR \& PO system & S5 \\
\hline 6 & Creating a supplier database & S6 \\
\hline 7 & Make a follow up checklist & S7 \\
\hline 8 & Negotiations with suppliers done by email & S8 \\
\hline 9 & Notification of shipping PO via messenger notification & S9 \\
\hline
\end{tabular}

Figure 6 - Mapping on the proposed improvements with the Effort and Impact Matrix 
User / Planner

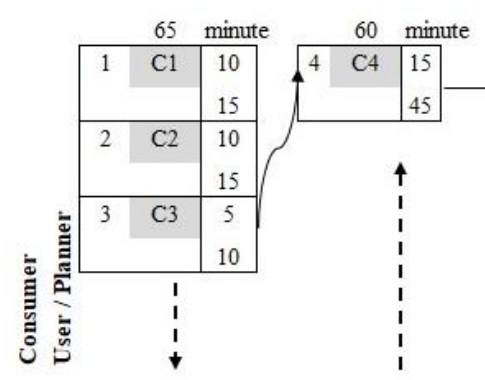

30 minut

\begin{tabular}{|ll|l|}
\hline 5 & C5 & 15 \\
& & 15 \\
\hline
\end{tabular}

i

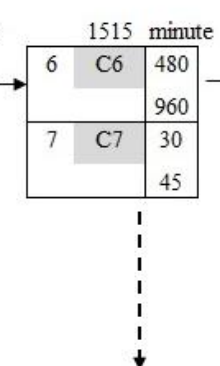

Total Consumer Time

1680 menit

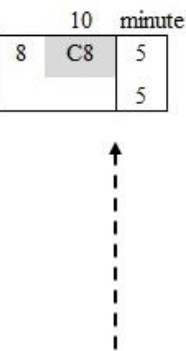

- $66.07 \%$

Non Value added time

$\longrightarrow \quad 33.93 \%$

$33.93 \%$

After Lean Consumption

Value Added Assessment

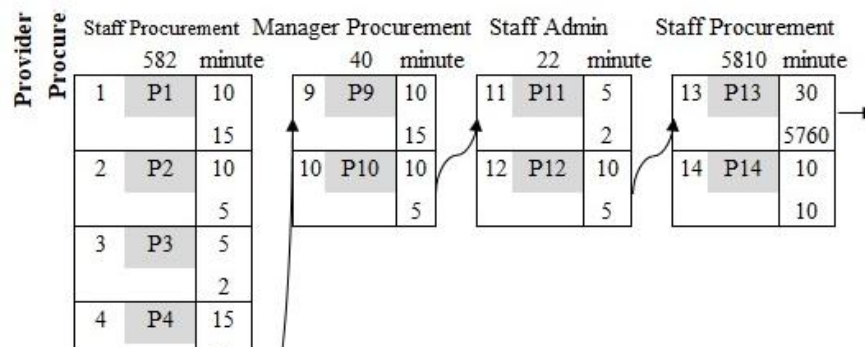

C1 Journey to Submit Form PR

$\mathrm{C} 2$ Communicate with procurement staff

C3 Handover of PR form

C4 Provide confirmation of the meeting schedule

C5 Provide confirmation of the meeting schedule

C6 Sample testing process

C7 Report on trial sample results

C8 Receive notifications for making $\mathrm{PO}$

P1 Receive PR form

P2 Check the completion of the approval

P3 Initials on handover of PR form

P4 Recap of PR documents

P5 Perform vendor searches

P6 Make a visit and meeting appointment

P7 Price request process

Check the completeness of legality documents and

them to the Procurement Manager for validation

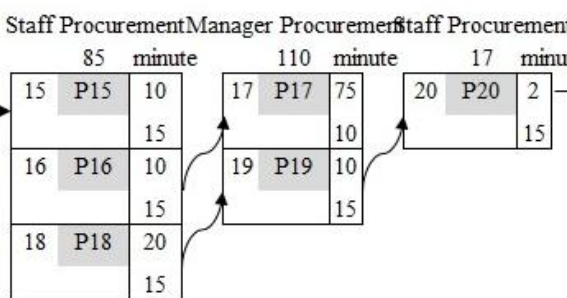

Director

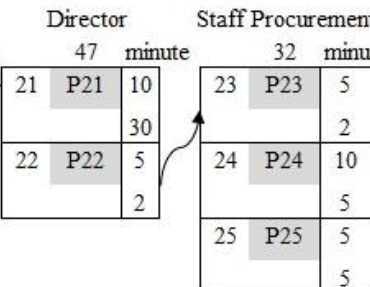

P9 Initials / validation of the completeness of legality documents

P10 Submit to admin staff

P11 Receive validated vendor completeness files

P12 Validated vendor registration

P13 Request samples to the supplier

P14 Provide samples to the user

P15 Receive reports on trial results

P16 Evaluate price quotes with Procurement managers and determine suppliers

P17 Bidding discussion and evaluation

P18 Make a PO and submit it to the Procurement manager

P19 Sign the PO and submit the signed PO to the Procurement staff

P20 Receive PO files that have been signed by the manager and forward it to the Director

P21 PO signing

P22 Submit the signed PO to the Procurement staff

P23 Receive PO file that has been signed by the Director

nit P24 Send POs to suppliers by email / fax

P25 Provide notification on the making of PO to the user / planner

aff Procurement Total Provider Time

Figure 7 - Simulation of LCM after Lean Consumption 
To solve this problem, the researcher used the next tool, FMEA table. FMEA aims to find the root problems of a work process. In addition, FMEA can also be used to predict a process failure so that proposed improvements can be made.

The first step in the analysis using FMEA, which is looking for a process with a high Risk Priority Number (RPN) value with a general standard> 100 , is considered a high RPN and needs improvement. Next, look at the Severity value if the high severity value can be considered to be a process improvement. Based on the results of the FMEA analysis, it can be seen that there are some high RPN values. Some of the processes with the highest RPN values are the handover of the purchase request form for the service user side by 150 points and the process of giving the results of a trial sample report. Meanwhile, in terms of service providers, processes with high RPN and the need for improvement are requesting samples to suppliers, discussions about supplier price quotes, and the process of approval of purchase orders by management. Meanwhile, the value of process severity analysis was not carried out because it was included in the process with a high RPN value.I

Based on the FMEA analysis, nine proposed corrective actions were taken to reduce the value of RPN (Risk Priority Number) based on the Flow Chart, Process Map, Cross Functional Flowchart and LCM. In the Improve stage, all proposed improvements will be selected using the Impact and Effort Matrix method.

The results obtained are that the total time required is reduced both from the service user side, from 2,374 minutes to 1,680 minutes or $29.23 \%$ improvement or from the service provider side, from 18,265 minutes to 6,745 minutes or $63.07 \%$. This improved process can be called Lean with class. The average settlement of requests also dropped from 51 days to 14 days or $66 \%$, better than the target in the Define stage. The Control Phase determines the new SOP, Change Management Plan and OCAP to maintain the consistency of repairs that are carried out.

Table 2 - Simulation of VAA after Lean Consumption

\begin{tabular}{|l|l|c|c|}
\hline \multicolumn{2}{|c|}{ Description } & $\begin{array}{c}\text { Customer } \\
\text { (Consumption Time) }\end{array}$ & $\begin{array}{c}\text { Provider } \\
\text { (Provision Time) }\end{array}$ \\
\hline Total Time & (a) & 1680 & 6745 \\
\hline Value Added & (b) & 570 & 572 \\
\hline Non Value Added & (c) & 1110 & 6173 \\
\hline$\%$ VA & $=(b) /(a) * 100 \%$ & $33.93 \%$ & $8.48 \%$ \\
\hline$\%$ NVA & $=(c) /(a) * 100 \%$ & $66.07 \%$ & $91.52 \%$ \\
\hline Value to Waste Ratio & $=(b) /(c) * 100 \%$ & $51.35 \%$ & $9.27 \%$ \\
\hline
\end{tabular}

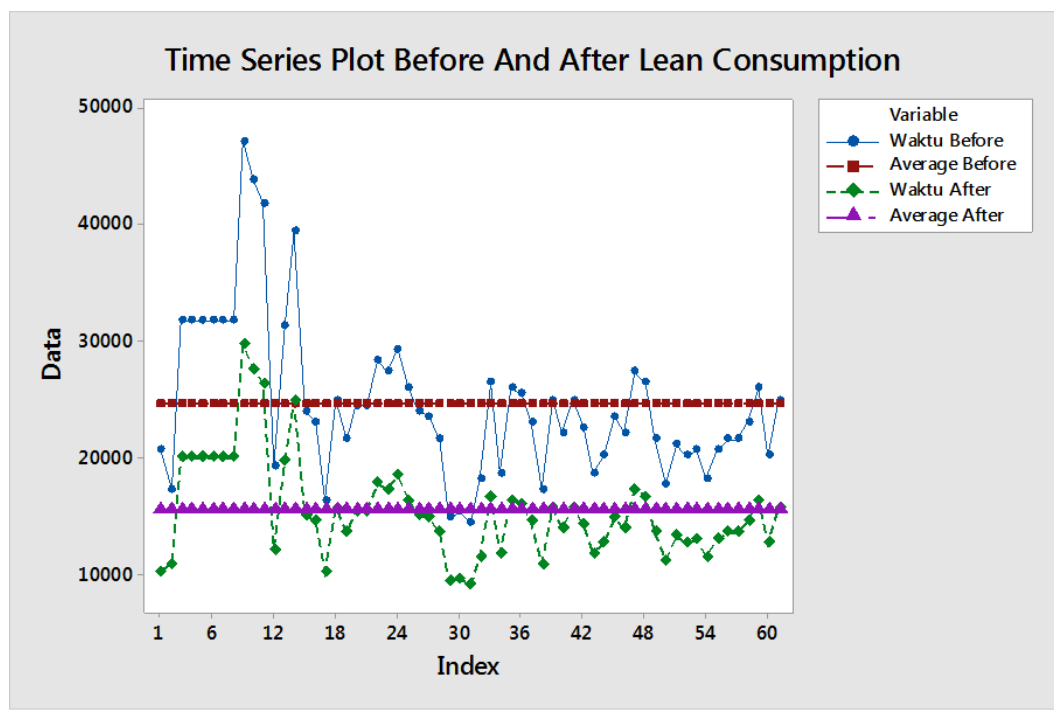

Figure 5 - Simulation of Time Plot Series after Lean Consumption 


\section{DISCUSSION OF RESULTS}

Based on the results of the analysis and discussion, it is necessary to have an idea to apply the Lean Consumption in the procurement department. There are three steps, namely starting the Lean Consumption program, running and managing the Lean Consumption program and maintaining the continuity of Lean Consumption program.

Lean Consumption Program is implemented in stages to provide time and opportunity for all teams to understand and accept the Lean Consumption as a new culture of work. That understanding to get new results must be in a new way, requiring time for each team member to fully accept.

Table 3 - Stages to start Lean Consumption

\begin{tabular}{|c|c|c|c|c|}
\hline $\begin{array}{c}\text { Make a team to implement } \\
\text { Lean Thinking }\end{array}$ & $\begin{array}{c}\text { Work plan of Lean } \\
\text { Thinking }\end{array}$ & $\begin{array}{c}\text { Training on Lean } \\
\text { Thinking }\end{array}$ & $\begin{array}{c}\text { Determine the } \\
\text { Focus of } \\
\text { improvement area }\end{array}$ & $\begin{array}{c}\text { Determine communication } \\
\text { media }\end{array}$ \\
\hline $\begin{array}{c}\text { Implementing team is } \\
\text { authorized to issue policies } \\
\text { in the form of SOP, } \\
\text { perform control and } \\
\begin{array}{c}\text { sueprvision related to Lean } \\
\text { Thinking program }\end{array}\end{array}$ & $\begin{array}{c}\text { Organize work plan } \\
\text { of Lean Thinking in } \\
\text { accordance wtih the } \\
\text { target of } \\
\text { achievement }\end{array}$ & $\begin{array}{c}\text { Provide insights on } \\
\text { lean Thinking to all } \\
\text { of procurement } \\
\text { team and user/ } \\
\text { planner }\end{array}$ & $\begin{array}{c}\text { Identity stages/ } \\
\text { processes of } \\
\text { improvement which } \\
\text { impat the company }\end{array}$ & $\begin{array}{c}\text { Organize materials and } \\
\text { methods of } \\
\text { communication correctly } \\
\text { based on targets in } \\
\text { delivering Lean Thinking } \\
\text { program }\end{array}$ \\
\hline
\end{tabular}

Running and managing Lean consumption program consists of three stages, namely program planning, program implementation and program follow-up (EPA, 2009). The first stage of program planning, at this stage, ensures that the Lean Consumption program is well planned in terms of scope and human resources. The second stage of program implementation, which is every Lean Consumption activity is a journey that requires facilitation and guidance as well as hard work from a highly committed team. The third step is the follow-up of the program, which is after the Lean Consumption project ends, effective follow-up is very important to complete the remaining or handed over action items to the team working in the process, to prevent setbacks, and to keep the focus-based improvement team in place continuously.

After an agency / institution has successfully completed a Lean Consumption project, it is important to think strategically about how to maintain improvements and, if desired, spread the spirit of Lean Consumption throughout the organization. There are four models for implementing Lean Consumption in organizations, along with specific steps to maintain and disseminate Lean consumption activities, namely Agency-Wide Model, Department/Division Model, Targeted Model and Grass Roots Model.

\section{CONCLUSION AND SUGGESTIONS}

The application of Lean Consumption in the improvement of the procurement process to procure new items and projects with internal customers is able to be applied with DMAIC and LCM methods with significant results. With the same characteristics and organizational models, this Lean Consumption can also be applied more broadly in other departments by following the same application steps. Lean Consumption Map is able to describe the overall Value Added Time and Non Value Added Time (waste) contained in the Customer side and from the Provider side well. LCM is able to display value flow information for administrative or service processes.

Compared to the use of Value Stream Map (VSM) which is commonly used before, there are many elements such as Data Box, Source Flow and Inventory that cannot be used to describe the flow of values in the public service process. In addition, the Value Stream Map prioritizes Physical Flow over Information Flow even though they are depicted on the same map. Lean Consumption Map (LCM) appears as a solution to describe the service process that prioritizes the flow of information rather than the physical or material flow. FMEA is superior in giving priority to improvement when compared to Fishbone Diagrams or 5Why Analysis which are generally used in the previous Lean method presented in A3 Report. 
This research is only focused on the internal procurement team, so the next research is expected to be able to examine other departments such as maintenance, marketing, warehouse and others. This research is also still focused on looking at the waste process recorded in TIMWOOD, it is expected that further research can see the waste process outside of TIMWOOD data; this is to verify and synchronize data waste. This research was conducted on one company, as we know there are many companies that can be the object of research, so the hope of further research can be done on several companies.

\section{REFERENCES}

1. Arafeh, M. (2016). Leveraging Six Sigma Tools and Methodology to Improve Student English Language Performance at Elementary School. American Journal of Operations Research, 6(July), 261-274. https://doi.org/http://dx.doi.org/10.4236/ajor.2016.64026.

2. Arfmann, D., \& Topolansky, F. (2014). The Value of Lean in the Service Sector: A Critique of Theory \& Practice. International Journal of Business and Social Science, 5(2), 18-25. https://doi.org/10.1108/20401461011049520.

3. Artadi, R., \& Syah, T.Y.R. (2019). Lean Service Design in Purchasing Order of Motorcycles: Case Study at Mandiri Utama Finance Branches Tangerang, Indonesia, 01(01), 1-5.

4. Berenyi, L., \& Banhegyesi, L. (2015). the Evaluation and Selection of Suppliers - in a Lean Approach. European Scientific Journal, University of Miskolc, Hungary, 11(7), 2538.

5. Cees, J., Weele, V., \& Arjan, J. (2005). Purchasing Portfolio Models: A Critique and Update.

6. Costantino, F., Di Gravio, G., \& Nonino, F. (2015). Insights from action research: Implementing an innovative lean procurement framework for global sourcing. International Business Management. https://doi.org/10.3923/ibm.2015.416.424

7. de Sousa, D. C., Gonçalves, R. F., Barboza, M., de Souza, R. R., \& Vendrametto, O. (2014). Lean Production and Just in Time: A Case Study of the e-procurement Application. IFIP Advances in Information and Communication Technology, 440(PART 3), 19-26. https://doi.org/10.1007/978-3-662-44733-8_3.

8. Drake, P. R., Myung Lee, D., \& Hussain, M. (2013). The lean and agile purchasing portfolio model. Supply Chain Management: An International Journal, 18(1), 3-20. https://doi.org/10.1108/13598541311293140.

9. Ginanjar, A., \& Syah, T. Y. R. (2019). Lean Government Concept and Design Over Service Administration in Indonesian ID Card, 01(01).

10. Hadriyanto, \& Syah, T. Y. R. (n.d.). Lean government.pdf.

11. Hartanto, A., \& Syah, T. Y. R. (2019). Lean Government Applied Concept in Mutation Service over Land and Building Tax at Badan Pendapatan Daerah (Bapenda ), 6-10.

12. Jones, D. T. (2005). Lean Consumption Lean Consumption by James P.

13. Leite, H. dos R., \& Vieira, G. E. (2015). Lean philosophy and its applications in the service industry: a review of the current knowledge. Production, 25(3), 529-541. https://doi.org/10.1590/0103-6513.079012.

14. Lizasoain, A., Tort, L. F., Garcl'lia, M., Gomez, M. M., Leite, J. P., Miagostovich, M. P., ... Victoria, M. (2015). No \{Title\}. Journal of Applied Microbiology, 119(3), $859\{$ \textendash\}867.

15. Maleyeff, J. (2014). Sustaining Public Sector Lean Six Sigma: Perspectives from North America. Management and Organizational Studies, 1(2), p92. https://doi.org/10.5430/mos.v1n2p92.

16. Nadeau, S. (2017). Lean, Six Sigma and Lean Six Sigma in Higher Education: A Review of Experiences around the World. American Journal of Industrial and Business Management, 07(05), 591-603. https://doi.org/10.4236/ajibm.2017.75044.

17. Partida, B., Framington, \& Aug, J. (2014). Adopting Lean Processes in Procurement Can Lead to Efficiency and Lower Costs, 18, 78-80.

18. Procter, S., \& Radnor, Z. (2014). Teamworking under Lean in UK public services: lean 
teams and team targets in Her Majesty's Revenue \& Customs (HMRC). International Journal of Human Resource Management, 25(21), 2978-2995. https://doi.org/10.1080/09585192.2014.953976.

19. Rüttimann, B. G., Fischer, U. P., \& Stöckli, M. T. (2014). Leveraging Lean in the Office: Lean Office Needs a Novel and Differentiated Approach. Journal of Service Science and Management, 07(05), 352-360. https://doi.org/10.4236/jssm.2014.75032.

20. Sridharran, R. (2008). Lean is about a shared process : James $P$., 1-4.

21. Sunaryanto, K., \& Syah, T. Y. R. (2019). Application of Lean Thinking Development: Case Study over Badan Pendapatan Daerah (Bapenda), South Tangerang Based on Lean Government, 20-26.

22. Widiantoro, B.C. (2015). 都市ガスコージェネレーションの計画設計と運用, VII(1), 82-91. 